\title{
Modeling of Char Hold-up and Char Particle Size Distributions in Circulating Fluidized Bed Combustors
}

\author{
K. Luecke, E.-U. Hartge, J. Werther
}

\begin{abstract}
Due to their ability of handling a wide range of fuels, power stations with circulating fluidized beds (CFB) can be used for co-combusting a variety of waste materials. By means of co-combusting wastes in power stations fossil fuels are saved and waste is thermally recycled. As an initial step for predicting the energy conversion efficiency of CFB combustors and for future emission modeling a model is presented which estimates the char hold-up and the spatial distribution of the char particle size distribution inside a CFB combustion chamber based on the fuel properties and the operating conditions of the combustor. Model calculations for different fuels have shown the strong influence of the fuel characteristic, i.e. the volatile content, and the reactor design, i.e. arrangement of fuel supply, on the char concentration in the combustion chamber.
\end{abstract}

\section{Introduction}

Due to their suitability for handling a wide range of fuels, power stations with circulating fluidized bed ( $\mathrm{CFB}$ ) combustors may be used for co-combustion of solid and paste wastes without requiring much additional investment. By means of co-combustion the finite resources of fossil fuels are saved and, simultaneously, waste material is thermally recycled. However, the energy conversion efficiency as well as the emission behavior of CFB combustors strongly depends on the fuel supplied, and thus may vary if fossil fuels are replaced by waste. An important characteristic of a fuel is its volatile content influencing the char hold-up in the combustion chamber. High char concentrations may lower the overall efficiency of the power plant due to char losses with the flue gas. On the contrary, the potential of char for reducing $\mathrm{NO}_{\mathrm{x}}$ emissions is well known [1]. The particle sized distribution (PSD) of the char accumulated in the CFB combustor differs significantly from the PSD of the fuel supplied to the combustor [2]. Therefore, as an initial step for predicting the energy conversion efficiency of CFB combustors and for future emission modeling a model is presented which estimates the char hold-up and the spatial distribution of the char PSD inside a CFB combustion chamber based on the fuel characteristics and the operating conditions of the combustor. Special emphasis is put on the description of large-scale CFB combustors, i.e. three-dimensional effects due to the point-wise introduction of the fuel and combustion air are considered in the model.

\section{Model Layout}

If the physical phenomena occurring inside the combustion chamber of a CFB boiler are to be described mathematically three subtopics have to be considered. First, the flow structure in terms of local gas and solids velocities and volume concentrations must be classified. Second, mixing of the solids and the gas phase has to be quantified, and, finally the com- 
bustion process itself, i.e. the reaction kinetic, has to be modeled. Employing the information of the three sub-models mass balances for the reactants at each finite control volume in the flow domain can be formulated.

\subsection{Flow Structure}

According to the axial solid volume concentration profile, the riser is axially divided into four different regions with different flow structures. In the bottom region of the combustion chamber with high solid volume concentrations, a shallow bubbling bed is assumed. The flow domain is subdivided here into a suspension and a bubble phase. Both, the bubble gas and the suspension gas flow upwards. The properties of both phases are calculated as summarized in [3]. As described in [4] the upper dilute region of the CFB combustion chamber is subdivided into an up-flowing lean suspension (lean phase) and descending clusters (dense phase), where the dense phase is assumed to be a particulate phase dispersed in the lean suspension. Both phases may coexist at any position in the flow domain, but the volume fraction of the dense phase is higher in the vicinity of the wall. In order to account for gas backmixing, it is assumed that the gas of the dense phase is entrained in the downward direction by the descending clusters. The upper dilute zone and the bottom zone are connected by the splash zone, which has the same structure as the upper dilute zone but with higher solid volume concentrations. The solids of the suspension phase are accelerated in the splash zone, until they reach the fully developed zone in the upper part of the riser. In both, the upper dilute and the splash zone, solid volume concentrations of the phases, gas and solid velocities and volume fractions of the dense phase have to be calculated. For this purpose, solid and gas balances are formulated and solved for each phase. Since the momentum balances are not solved, additional information from measurements is necessary: one pair of horizontal solid mass flux profiles of the up-flowing and descending solids in the combustion chamber obtained from suction probe measurements is needed as input data. A method, outlined in [4], allows the extrapolation of this pair of mass flux profiles to a 3D distribution of solid mass fluxes throughout the whole flow domain. The exit region is modeled as a simple continuous stirred-tank.

\subsection{Gas and Solids Mixing}

According to newer findings on solids mixing in the bottom zone of CFBs, the solids in the shallow bottom bed can be assumed to be ideally mixed in vertical direction [5]. The limited mixing in horizontal direction which will lead to concentration gradients can be described with a constant dispersion coefficient $D_{s}$ taken from [5]. The gas phase is not mixing in the horizontal direction but is assumed to pass the bottom bed in plug-flow. In the upper dilute and splash zones vertical dispersion is neglected due to the overwhelming convection forces in this direction. Horizontal gas mixing is modeled by introducing a Peclet number [6]. However, comparison with measurements suggested that Pe derived in the small-scale cold unit underestimates the horizontal dispersion in large-scale combustors. Thus, a Peclet number of 150 was applied in the present model. Due to a lack of information horizontal solids dispersion was described in analogy to the gas phase mixing with the same Pe number.

\subsection{Reaction Kinetic Model}

Devolatilization. Solid fuels consist of volatiles and char. Upon entering the reactor a solid fuel particle heats up and simultaneously looses its volatile matter. During this time the fuel particle will already be spread over the cross-sectional area of the bed by dispersion and convection which is imposed mainly by the flux of entering fuel and recycled ash. The volatile release rate is assumed to be constant and independent of the composition of the surrounding gas and solids. The only parameter needed for this sub-model is the total devolatilization time 
of a single particle which might be calculated according to [7]. Since the volatiles are assumed to be released in the bottom zone only the fuel distribution process is described as follows:

$$
\begin{gathered}
\frac{\partial}{\partial t}\left(C_{f}\left(1-\varepsilon_{b}\right)\right)=\frac{\partial}{\partial x}\left(D_{s} \frac{\partial\left(C_{f}\left(1-\varepsilon_{b}\right)\right)}{\partial x}\right)+\frac{\partial}{\partial y}\left(D_{s} \frac{\partial\left(C_{f}\left(1-\varepsilon_{b}\right)\right)}{\partial y}\right) \\
-\frac{\partial}{\partial x}\left(u_{s, x} C_{f}\left(1-\varepsilon_{b}\right)\right)-\frac{\partial}{\partial y}\left(u_{s, y} C_{f}\left(1-\varepsilon_{b}\right)\right)
\end{gathered}
$$

The boundary conditions are given as zero fluxes through the walls and the initial conditions are a fuel char field of $C_{f}(x, y, t=0)=0$ at any position combined with an initial feed impulse at the feed chute. Since char starts burning only after complete devolatilization, equation (2.1) does not include a reaction term. This sub-model is independent of the combustion model. It is linked to the combustion model only by the local release rates of volatiles and char, which enter the combustion model as local source terms. The char sources are proportional to the fuel char field $C_{f}\left(x, y, t=t_{v}\right)$ after complete devolatilization; the volatile sources are obtained by adding up the released volatiles for each individual time step, which depends on the instantaneous fuel char field and the volatile release rate. The volatiles are released as $\mathrm{CO}$, $\mathrm{CO}_{2}, \mathrm{CH}_{4}, \mathrm{H}_{2}, \mathrm{H}_{2} \mathrm{O}$, and $\mathrm{O}_{2}$, the fractions of which are calculated on the basis of the ultimate analysis of coal and char.

Combustion. The subsequent combustion model describes both the further reactions of the volatiles in the gas phase and the burn-up of the residual char particles. The gas phase reactions occur at finite rates, thus, the model can take account for incomplete oxidation of combustible gas species. The char burn-up is modeled according to the shrinking spherical particle model. The stoichiometric conversion of char-C to $\mathrm{CO}$ and $\mathrm{CO}_{2}$ can be written as

$$
\mathrm{O}_{2}+\Theta \mathrm{C} \rightarrow 2(\Theta-1) \mathrm{CO}+(2-\Theta) \mathrm{CO}_{2}
$$

where the mechanism factor $\Theta$ determines the ratio of $\mathrm{CO}$ to $\mathrm{CO}_{2}$ produced and is calculated as suggested by [8]. The carbon consumption in terms of $\mathrm{kmol} / \mathrm{s}$ depends on the local oxygen concentration in the bulk phase and the surface of the char particle:

$$
r_{\mathrm{C}}=\Theta \cdot r_{\mathrm{O}_{2}}=-\Theta \cdot K \cdot A_{P} \cdot C_{\mathrm{O}_{2}}^{*}
$$

The apparent kinetic constant $\mathrm{K}$ takes into account both the chemical reaction on the particle surface and the transport through the gas boundary layer. For the particle diameters investigated none of the mechanisms are prevailing, i.e. the char burn-up is controlled by both chemical reaction and gas transport (Fig. 1).

\section{Application of the Model}

The model was applied to the geometry and the operating conditions of the $12 \mathrm{MW}_{\text {th }} \mathrm{CFB}$ combustor at Chalmers University of Technology (CUT) in Göteborg/Sweden. The combustor which is described in detail in [9] has a square crosssectional area of $1.6 \times 1.6 \mathrm{~m}^{2}$ and a total height of

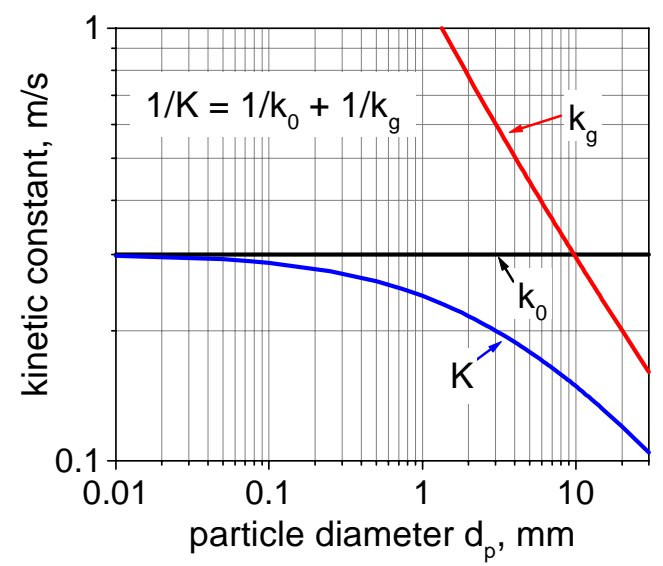

Fig. 1. Influence of $d_{p}$ on the kinetics under CFB conditions. 
Tab. 1. Properties of the fuels applied in the simulations

\begin{tabular}{l|ccc}
\hline & Coal 1 [9] & Coal 2 [2] & Wood [9] \\
\hline Water (wt-\%, raw) & 14.8 & 14.5 & 43.1 \\
Ash (wt-\%, raw) & 6.6 & 10.8 & 0.4 \\
Volatiles (wt-\%, daf) & 39.9 & 35.8 & 81.6 \\
Ultimate (wt-\%, daf) & & & \\
C & 79.8 & 81.5 & 50.60 \\
H & 5.3 & 5.7 & 5.90 \\
O & 12.6 & 10.3 & 43.24 \\
S & 0.7 & 0.9 & 0.04 \\
N & 1.6 & 1.6 & 0.22 \\
\hline
\end{tabular}

daf-dry and ash free
$13.5 \mathrm{~m}$. Fuel is injected from one side into the bottom part of the furnace. From the opposite side recycled bed material and ash are returned into the riser. Two different air staging techniques have been simulated: no staging where all the combustion air is supplied to the gas distributor at the bottom and normal staging where about $35 \%$ of the total air are injected as secondary air at a

height of $2.2 \mathrm{~m}$ above the distributor. Despite the difference in the air supply all the other operating conditions are quite similar for both staging techniques, i.e. a superficial gas velocity at the top of the riser of $6.3 \mathrm{~m} / \mathrm{s}$, an excess air ratio of 1.21-1.23, a reactor temperature of $850^{\circ} \mathrm{C}$ and a total pressure drop of 7,000 Pa. Due to a lack of measurements an external solids recirculation rate of $20 \mathrm{~kg} / \mathrm{m}^{2} / \mathrm{s}$ is assumed for both cases. The fuel properties are summarized in Tab. 1. Coal 1 was applied under normal staging conditions, coal 2 in the no staging case.

\section{Results and Discussion}

In Fig. 2 the evolution of the fuel feed sources, i.e. the sum of char and volatiles to be released, in the bottom bed is depicted. In the beginning of the devolatilization/fuel distribution process a clear maximum near the fuel feed chute is visible. However, after $20 \%$ of the total devolatilization time the peak has been dropped considerably and just before completion the gradients have been almost leveled off. Near the solids return leg a minimum occurs. This is due to convective fluxes generated by the recycled ash which are driving the fresh fuel particles away from this point. In the distribution process the particles are loosing mass due to the volatile release. Thus, the fuel source integral is reduced in the course of time. The outcome of the fuel distribution model are local char sources for each particle class and cumulative local volatile sources (Fig. 3). The results for 2 out of 8 particle classes are shown. With increasing particle diameter the time for devolatilization increases and, consequently, the char sources are more evenly distributed. The volatile source field depicts somehow steeper gradients and a higher peak near the fuel chute. This is reasonable, since the volatiles are released during the whole devolatilization time $\left(0 \leq t \leq t_{v}\right)$ whereas char is "released" only at $t=t_{v}$. The local sources enter the subsequent combustion model. Under steady state conditions a constant fuel loading with a certain PSD will be established in the combustion chamber based on the operating conditions and the fuel properties.
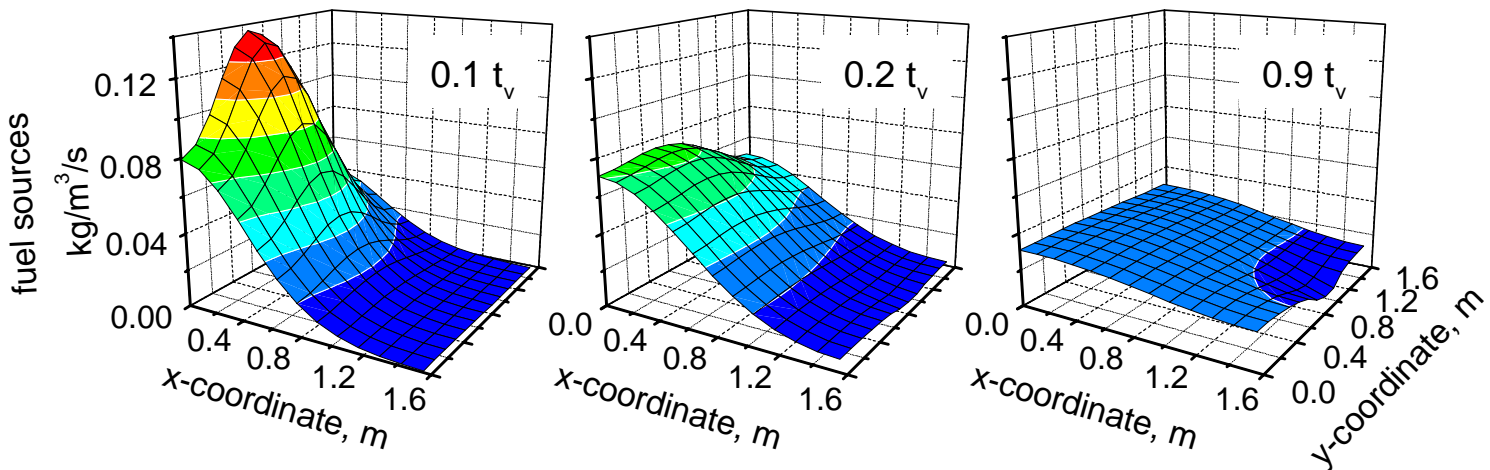

Fig. 2. Fuel sources during fuel distribution process in the bottom zone. No staging conditions. Fuel particle class: $0.71 \mathrm{~mm}<d_{p}<1.4 \mathrm{~mm}$ corresponding to $t_{v}=9.2 \mathrm{~s}$. 

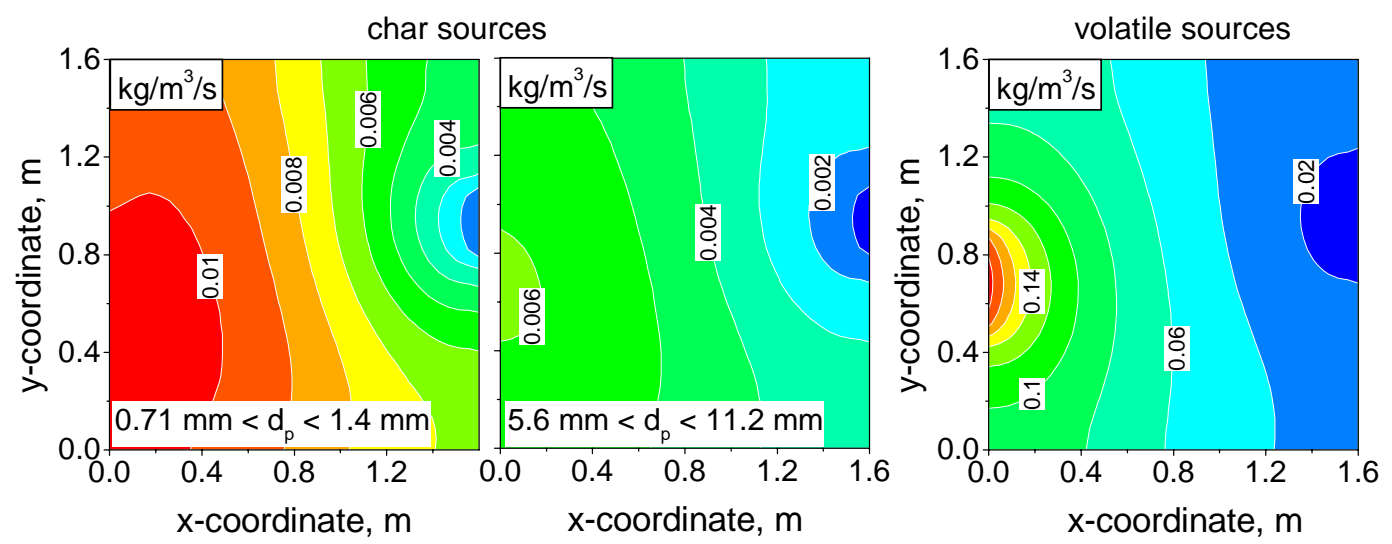

Fig. 3. Local char (left) and volatile (right) sources. Particle class $0.71 \mathrm{~mm}<d_{p}<1.4 \mathrm{~mm}$ corresponds to $19.7 \%$ of the feed, $5.6 \mathrm{~mm}<d_{p}<11.2 \mathrm{~mm}$ to $6.9 \%$.

Fig. 4 compares the computed char particle size distribution with measurements in the bottom part of the CFB boiler at CUT under no staging conditions. The model is well able to predict the shift of the original fuel PSD to enlarged char particle diameters under steady state

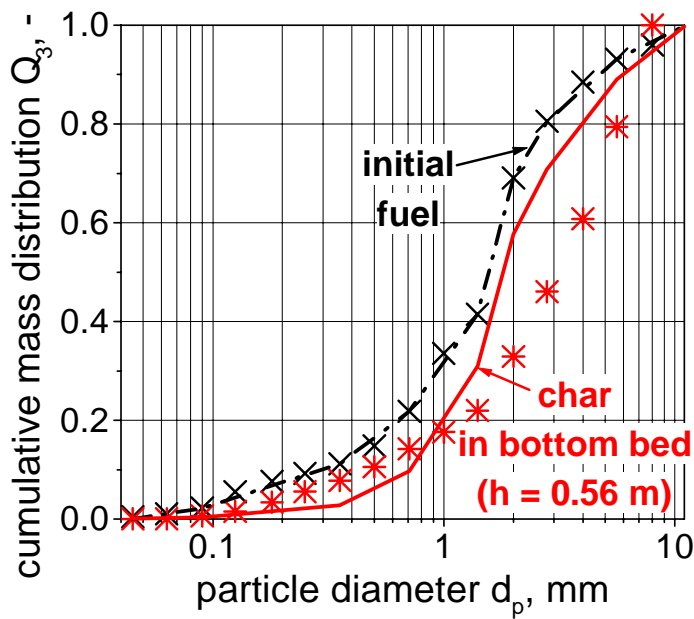

Fig. 4. Measured (asterisks) and calculated (solid line) char PSD conditions. This shift is due to slow combustion rates of large particles decelerated by the larger gas diffusion resistance (cf. Fig. 1). If the local concentrations and the local PSD of the char particles are known an effective kinetic constant describing the local oxygen consumption can be computed. The resulting $\mathrm{O}_{2}$ profiles are compared with measurements in Fig. 5. The agreements with available data are in both cases satisfactorily. In the no staging case an elevated $\mathrm{O}_{2}$ consumption above the fuel chute is predicted since here most of the volatiles are released. At the location where the recycled bed ash enters virtually no volatiles and the lowest char concentrations are found. Thus, here the highest $\mathrm{O}_{2}$ concentrations are observed. Especially from the normal staging case it becomes obvious that horizontal gas mixing is very slow compared to vertical convection. The height of the combustor is merely sufficient to even out the horizontal gradients.

Finally, calculations with wood instead of coal revealed the influence of the fuel volatile content on the combustor char hold-up. Combusting wood results in a char fraction in the bed material at the riser exit of $0.3 \mathrm{wt} .-\%$, whereas calculations with coal lead to $1.0 \mathrm{wt} .-\%$.
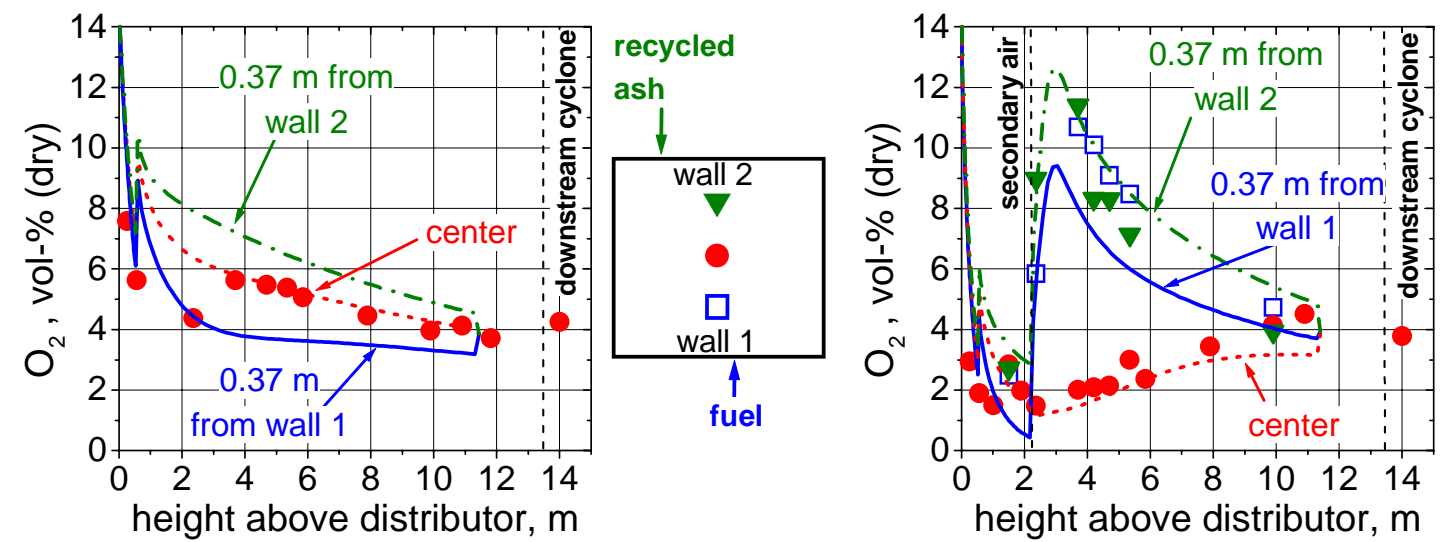

Fig. 5. Oxygen profiles in the case of no staging (left) and normal staging (right). 


\section{Conclusions}

A 3D semi-empirical model approach has been chosen to describe the phenomena inside the combustion chamber of a CFB boiler. The combustion of a single fuel particle was described by two independent consecutive steps: devolatilization and burn-up. The burn-up of the residual char was described in analogy to the shrinking spherical particle model in order to obtain information about the char particle size distribution under steady state conditions. In comparison with measurements a shift of the initial fuel PSD to larger diameters for the char PSD was simulated due to the higher conversion ratios of small fuel particles. The resulting oxygen profiles agree well with the measured profiles for both the no staging and the normal staging case. For high volatile fuels only a low char hold-up can be expected. In addition, model calculations show the influence of the fuel feed chute and solids return line on the spatial concentration distributions of the reactants inside the combustion chamber.

\section{Nomenclature}

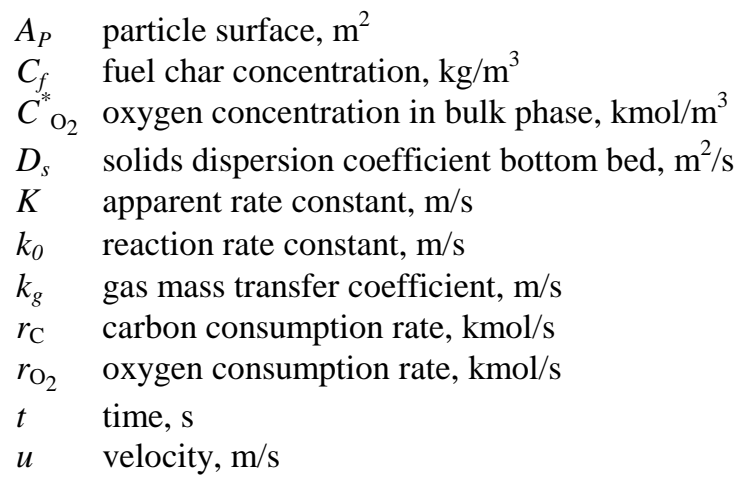

$\begin{array}{ll}x & \mathrm{x} \text {-coordinate, } \mathrm{m} \\ y & \mathrm{y} \text {-coordinate, } \mathrm{m}\end{array}$

\section{Greek letters}

$\varepsilon_{b} \quad$ bubble volume fraction, $\mathrm{m}^{3} / \mathrm{m}^{3}$

$\Theta \quad$ kinetic mechanism factor, -

$\begin{array}{ll}\text { Indices } & \\ s & \text { solids } \\ v & \text { devolatilization }\end{array}$

\section{References}

[1] Leckner, B., Karlsson, M.: Gaseous emissions from circulating fluidized bed combustion of wood. Biomass and Bioenergy, Vol. 4, 1993, pp. 379-389.

[2] Kilpinen, P.: Investigation of $\mathrm{N}_{2} \mathrm{O}$ Reduction Processes in Circulating Fluidized Bed Combustion Chambers. ECSC coal RTD program, project no. 7220-ED/087, research final report, 2000.

[3] Werther, J., Wein, J.: Expansion Behavior of Gas Fluidized Beds in the Turbulent Regime. AIChE Symp. Ser. 90, Vol. 301, 1994, pp. 31-44.

[4] Kruse, M., Werther, J.: 2D gas and solids flow prediction in circulating fluidized beds based on suction probe and pressure profile measurements. Chem. Eng. Proc., Vol. 34, 1995, pp. 185-203.

[5] Schlichthärle, P.: Fluid Dynamics and Mixing of Solids and Gas in the Bottom Zone of Circulating Fluidized Beds, Shaker Verlag, Aachen, 2000, 128 pp.

[6] Kruse, M., Schönfelder, H., Werther, J.: A Two-Dimensional Model for Gas Mixing in the Upper Dilute Zone of a Circulating Fluidized Bed. Can. J. Chem. Engng., Vol. 73, 1995, pp. 620-634.

[7] Ross, D.P., Heidenreich, C.A., Zhang, D.K.: Devolatilization times of coal particles in a fluidised bed. Fuel, Vol. 79, 2000, pp. 873-883.

[8] Arthur, J.R.: Reactions between Carbon and Oxygen. Trans. Faraday Soc., Vol. 47, 1951, pp. 164-178

[9] Åmand, L.-E., Lyngfelt, A., Karlsson, M., Leckner, B.: Fuel Loading of a Fluidized Bed Combustor Burning Bituminous Coal, Peat or Wood Chips. Mechanical and Vehicular Engineering - Chalmers University of Technology, Report A 97-221, 1999, 21 pp. 


\section{Authors}

Dipl.-Ing. Luecke, Karsten

Dr.-Ing. Hartge, Ernst-Ulrich

Prof. Dr. Ing. Werther, Joachim

Technical University Hamburg-Harburg,

D-21071 Hamburg, Germany

E-mail: karsten.luecke@tu-harburg.de 